\title{
Additive Manufacturing of Reinforced Concrete-Development of a 3D Printing Technology for Cementitious Composites with Metallic Reinforcement
}

\author{
Martin Classen ${ }^{1,2, *(\mathbb{D})}$, Jan Ungermann ${ }^{2}(\mathbb{D})$ and Rahul Sharma ${ }^{3} \mathbb{D}$ \\ 1 Department of Civil Engineering, KU Leuven, 2860 Sint-Katelijne-Waver, Belgium \\ 2 Institute of Structural Concrete, RWTH Aachen University, 52062 Aachen, Germany; \\ jungermann@imb.rwth-aachen.de \\ 3 Institute of Welding and Joining Technology, RWTH Aachen University, 52062 Aachen, Germany; \\ sharma@isf.rwth-aachen.de \\ * Correspondence: martin.classen@kuleuven.be or mclassen@imb.rwth-aachen.de
}

Received: 6 May 2020; Accepted: 27 May 2020; Published: 29 May 2020

\begin{abstract}
Reinforced concrete (RC) is by far the most widely used composite material in the world. Despite the enormous economic importance of RC construction, there is a lack of viable concepts for its digital fabrication. While 3D printing of plain concrete has been pushed forward by a growing research community in recent years, methods for integration of steel reinforcement have only scarcely been researched and little attention has been payed to meet the practical requirements of construction sites and prefabrication plants. Therefore, full-scale implementations of current approaches are hardly available. Based on both, a sound review of R\&D for digital fabrication of RC structures and an analysis of practical requirements, the present paper proposes a novel 3D printing process for RC structures, called Additive Manufacturing of Reinforced Concrete (AMoRC), viable for real-world application. In this hybrid process, consisting of an intermittent stud welding process and a continuous concrete extrusion process, segmented steel reinforcing bars are joined to form a three-dimensional reinforcement mesh and simultaneously encased with extruded concrete. The paper describes the conceptual design and development of the process and demonstrates the results of preliminary investigations on its feasibility. As AMoRC enables the operation of rebar welding and concrete extrusion process with synchronized feed rates, combination of both processes in one hybrid print head for digital fabrication of RC is a key-advantage of the proposed method.
\end{abstract}

Keywords: digital fabrication with concrete; 3D printing; integration of reinforcement; AM; stud welding; extrusion of concrete

\section{Introduction}

Additive Manufacturing (AM), also known as 3D printing, is an emerging production method in various industry sectors. Since its development by Hull [1] in 1986 and its introduction to the manufacturing industry, it has been used almost exclusively for rapid prototyping in development departments. Today, however, more and more products are manufactured by AM, partly also in series production (e.g., aerospace, medical sector) [2]. The 3D printing process begins with the creation of a virtual 3D model in a Computer Aided Design (CAD) environment, which is cut by slicing software into $2 \mathrm{D}$ slices of a thickness corresponding to the filament thickness. The workpiece, sometimes geometrically complex, is then built up in layers using a computer-controlled print head. For this purpose, the print head, guided by a robot arm or a gantry system, applies a printable material layer by 
layer, which hardens during the printing process. In addition to processes based on material extrusion, there is a large variety of other additive manufacturing processes like layer laminated manufacturing or powder bed fusion. An overview is presented in [3].

In many branches of industry, the workpieces to be printed are small components made of polymers, steel or ceramics, which in terms of size are significantly smaller than the dimensions commonly used in the construction industry. However, since the mid-1990s AM has also been gradually entering the construction sector.

Khoshnevis presented the Contour Crafting (CC) system [4], which was the first implementation of an additive manufacturing process for cement-based materials. As the name Contour Crafting suggests, only the outer contour of a component is printed, while the inner cavity is filled with self-compacting concrete. Conventional formwork can be avoided by this method. A short time later, Loughborough University developed another extrusion-based process called Concrete Printing, which is capable of producing not only the outer contour but entire structures by means of additive production [5,6]. Under the influence of this pioneering work, numerous universities and companies have started to develop $3 \mathrm{D}$ printing technologies for concrete. Today, research into the additive manufacturing of concrete is the subject of a rapidly growing global research community. Most research work to date is centered around the specific adjustment of fresh concrete properties to make concrete printable (e.g., rheological properties for pumping and depositing of concrete). An overview on research activities in this field can be found in $[7,8]$. In recent years, various technologies for 3D printing of plain concrete have been developed, mainly based on the principle of extrusion of fresh concrete. At the same time, the number of demonstration projects and prototypical applications of printed concrete has increased considerably. In Europe, the work of Mechtcherine (TU Dresden) [9,10], De Schutter (University of Ghent) [11,12] and Wolfs (Eindhoven University of Technology) $[13,14]$ is particularly noteworthy. However, structures and components made of plain concrete that can be produced with today's methods are rarely suitable for use in real structures, because they are often characterized by brittle failure behavior and insufficient load-bearing capacities.

In the future, methods will be required that enable the integration of steel reinforcement into printing process and thus allow for additive production of reinforced concrete.

\section{Existing Concepts for Reinforcement Integration}

\subsection{Overview}

It is already foreseeable today that additive manufacturing of concrete using extrusion-based deposition methods has groundbreaking potential and can fundamentally change the way we build. However, in many cases, the non-reinforced concrete members produced with previous additive manufacturing strategies are not sufficient to reliably resist the loading actions real structures are exposed to. Consequently, methods will be required that enable the integration of steel reinforcement into the printing process and thus the additive production of reinforced concrete in the future. So far, it is largely unclear how steel reinforcement can be integrated into the 3D concrete printing process. Today's solutions for reinforcement integration are mainly of conceptual nature, and only few research studies have been carried out, so far [15].

Figure 1 gives an overview of the most important concepts. In detail these are:

(a) Contour Crafting with post-installed reinforcement: Additive production of the outer contour of the member with unreinforced concrete. The 3D-printed contour serves as a lost formwork. In a second step, reinforcement is conventionally (manually) post-installed and the contour is subsequently filled with concrete (e.g., [4], Win Sun [16], Apis Cor [17]).

(b) Special case of (1), where in addition to the contour of the member, the interior part of the member is also printed with unreinforced concrete. Here, channels are left out in the plain concrete for post-installation of reinforcement bars, external reinforcement installation or prestressing with tendons $[18,19]$. 
(c) Encasing of (manually) preinstalled steel reinforcement with extruded concrete from two or more nozzles without external formwork (e.g., HuaShang Tengda Ltd., Beijing, China) [20].

(d) Spraying of (manually) preinstalled steel reinforcement with shotcrete without external formwork (so-called Shotcrete 3D printing (SC3DP) of the Technical University of Braunschweig) [21,22].

(e) Multi-arm printing of steel reinforcement and concrete: Reinforcing steel and concrete are produced in parallel by independent printing processes for concrete extrusion or shape welding (TU Dresden) [11,23].

(f) Mesh Mold approach: Robot-supported production of complex-shaped spatial steel meshes into which concrete is subsequently casted. Besides their function as reinforcement, the steel meshes also serve as lost formwork (ETH Zurich) [24].

(g) Online reinforcement integration in the concrete filament: In this process, formable (flexible) reinforcement elements (textile reinforcement, cables, etc.) are fed to the extruded concrete filament in the print head so that the resulting component is reinforced parallel to the extrusion direction [25];

(h) Layer-by-layer installation of reinforcing elements that can be plugged or screwed into each other between successive concrete extrusion layers. Installation of reinforcement elements is either done manually or by robot [26].
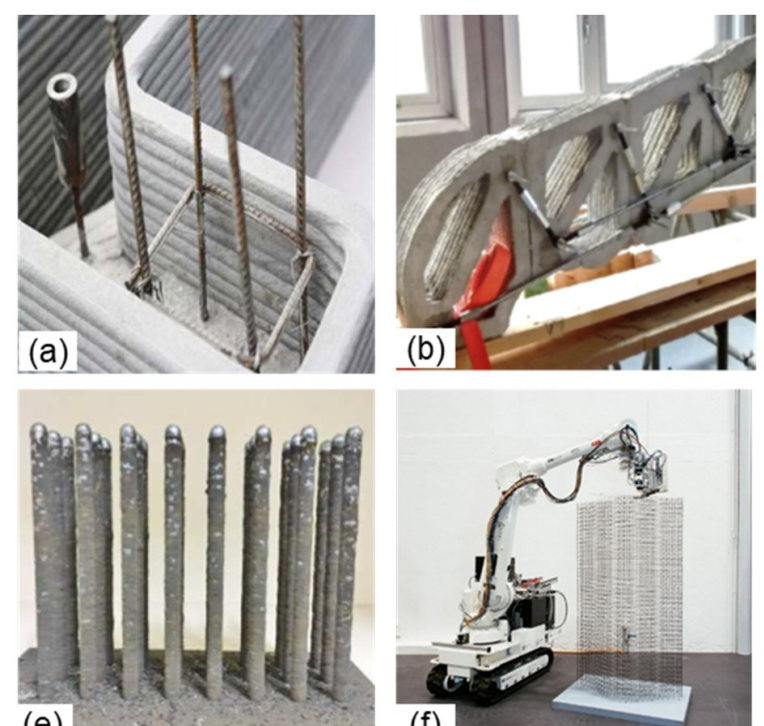

(e)

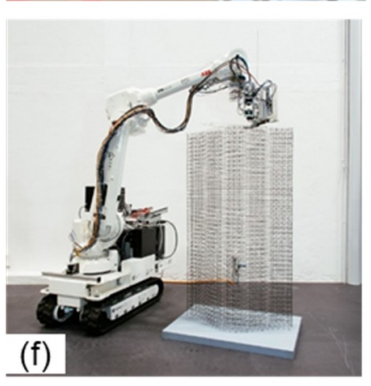

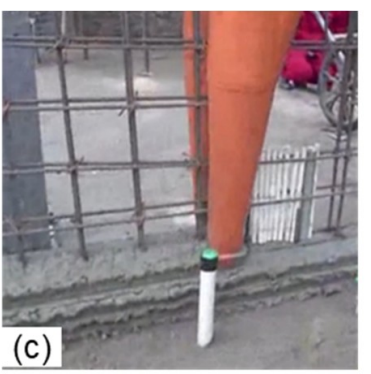

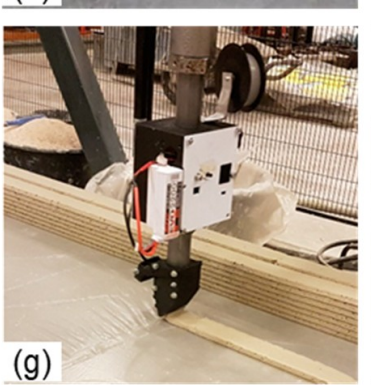

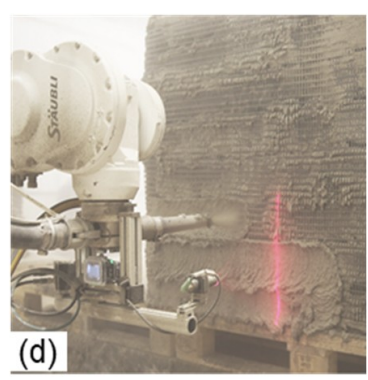

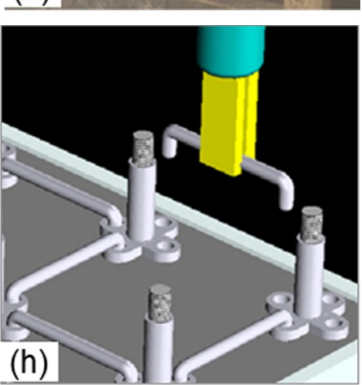

Figure 1. Concepts for integration of reinforcement (a-h) into 3D concrete printing processes.

\subsection{Review of Existing Methods}

The methods (a)-(h) show the broad range of possible solutions for reinforcement integration which differ considerably in terms of both the degree of automation and the practical maturity. Contour crafting with post-installation of reinforcement (a), (b) can be understood just as a short-term transition solution with regard to the degree of automation. Post-installation of (vertical) reinforcement within the narrow contour of a component is circumstantial and extremely labor-intensive due to the limited lateral working space (Figure 1a,b). In this context, encasing of reinforcement with multi-nozzles (c) or spraying shotcrete (d) to a manually pre-installed reinforcement is a much more promising alternative from a process engineering point of view. An example of the implementation of (c) is the two-nozzle concrete printer developed for wall panels by the Chinese manufacturer HuaShang Tengda Ltd. [20], which encases reinforcement fabrics with a fork-shaped nozzle from two sides (Figure 1c). The disadvantage of this technology is that the producible wall height is limited by the fork length of the printing head and intensive manual finishing is required to achieve an adequate surface quality. On the other hand, a greater spatial design flexibility is offered by enclosing the reinforcement with shotcrete (Figure 1d), which was developed at the University of Braunschweig [21,22]. A challenge in concrete 
deposition is to clasp around the pre-installed reinforcement in such a way that shadowing effects are avoided, which can lead to the formation of defects in the vicinity of the reinforcement. Within both methods (c), (d) the reinforcement structure has to be conventionally (manually) pre-installed before placing the concrete which is unfavorable compared to fully digital production processes. In contrast to encasing pre-installed reinforcement, Mechtcherine [11,23] proposes additive manufacturing of reinforcement (Figure 1e). The so-called wire arc additive manufacturing (WAAM) based on a metal arc gas welding process (MAG) allows the reinforcement to be built-up by incremental weld points. Comparable approaches of shape welding have been used in a research project on pin connectors for steel-concrete composite structures [27-29] and are also already being used in the printing of pure steel structures [30]. The overall process proposed in [23] is called parallel "multi-arm printing of concrete and reinforcement". However, the proposed concept neither specifies how the printing processes for steel and concrete will interact nor which methods will be used to place concrete around the printed reinforcement. It is also important to note that the incremental build-up of the reinforcement from individual weld points requires considerable energy for the melting of steel. Furthermore, heat accumulation occurring within the printed rebar will significantly affect the material properties of reinforcing steel. However, presumably the biggest obstacle for a real-scale implementation of this process is the limited melting rate of the welding process (approx. 1-4 kg/h) [31], which would massively inhibit and slow down the concrete extrusion process.

The Mesh Mold process [24] (f) allows a faster production of complex-shaped reinforcing elements using a resistance welding robot (Figure 1f). In this process, the reinforcement bars are installed at small spacing. Thus, the dense steel mesh combines the functions of reinforcement and formwork and allows for conventional pouring of concrete. However, mesh mold structures have small concrete cover, for which critical aspects like protection of reinforcement against corrosion as well as a sufficient bond between steel and concrete have not been resolved, so far.

First, concepts for combined print heads for reinforcement and concrete rely on techniques for simultaneous insertion/unrolling of textile or metallic, thread-like reinforcement elements from coils in the print head [25]. The so-called online reinforcement integration in the concrete filament (g) allows for an excellent durability of the reinforcement, because the flexible reinforcement elements are already fed to the extruded concrete filament in the print head. However, such methods only allow for one-dimensional integration of reinforcement which does not cross the interface between different concrete layers. The concrete interfaces—as the main weak points of the printed structure-are therefore unreinforced. In addition, these approaches are limited to reinforcement with constant diameter and the material laws and bond properties of such reinforcements are unknown so far.

In order to avoid unreinforced concrete layer interfaces, Khoshnevis [26] proposed to assemble the reinforcement structures in layers from form-fitting reinforcement elements (by screwing, plugging or interlocking) and to subsequently encase them with extruded concrete (Figure 1h). In this concept, the time-consuming connection of the reinforcing elements is carried out by hand or robots after completion of each concrete layer before the next concrete layer is deposited. However, the coupling of reinforcing elements is time-consuming, and their production cost intensive. It is interesting to note that, generally, methods (e)-(h) do not allow for use of conventional reinforcing steel, which has been researched and optimized (e.g., in terms of bond properties) over several decades.

The review and analysis of the state of research reveals that some of the proposed concepts can only be realized in combination with comprehensive (manual) work steps. Other approaches have not yet been fully developed, have not been validated on a large scale, are not realistically feasible under site conditions or neglect essential requirements for the properties of the printed composite material (e.g., continuity of reinforcement across concrete interfaces, bond and durability of reinforcement, etc.). Obviously, the development of new RC printing methods that are explicitly orientated towards practical application in the construction sector is urgently required. 


\section{Additive Manufacturing of Reinforced Concrete Process (AMoRC)}

\subsection{Requirements for a Viable 3D Printing Procedure of Reinforced Concrete}

Reinforced concrete (RC) is by far the most widely used composite material in the world. Despite the enormous economic importance of RC construction, there is a lack of viable concepts for its digital production. In consequence, RC structures are still manufactured almost entirely conventionally (by hand). The aim of the research presented in this paper is to design a method that overcomes the limiting properties and drawbacks of previous automated methods with regard to the manufacturing process and the properties of the printed material. The essential requirements and target values of the method to be developed for 3D printing of RC are listed in Table 1, separated according to the dimensions process engineering, structural behavior, durability, and economic efficiency.

Table 1. Requirements for a viable 3D printing process for reinforced concrete.

\begin{tabular}{|c|c|}
\hline Dimension & Requirement/Target \\
\hline Process engineering & $\begin{array}{l}\text { Printing of RC by use of a combined print head for steel and concrete or with } \\
\text { - } \quad \text { Unify/synchronize the feed rates of reinforcement mesh production and } \\
\text { concrete extrusion } \\
\text { - Use of cost-effective, widely available, and comprehensively researched } \\
\text { components (concrete and reinforcing steel) } \\
\text { - Large-scale feasibility for construction sites/ precast concrete plants }\end{array}$ \\
\hline Structural behavior & $\begin{array}{l}\text { - } \quad \text { Continuity of reinforcement across printed concrete interfaces } \\
\text { - } \quad \text { thew energy input during welding of reinforcement in order to minimize } \\
\text { - } \quad \text { Ensuring sufficient bond between reinforcement and concrete } \\
\text { - Adapting reinforcement layout to internal flow of forces e.g., through } \\
\text { variability of used reinforcement diameters }\end{array}$ \\
\hline Durability & $\begin{array}{l}\text { - Sufficient concrete cover and avoidance of defects to ensure protection of } \\
\text { reinforcement against corrosion }\end{array}$ \\
\hline Economic efficiency & $\begin{array}{l}\text { - Use of cost-effective and widely available building materials (concrete and } \\
\text { reinforcing steel) in order to use existing supply chains in the construction } \\
\text { industry and reduce the cost of R\&D } \\
\text { - Low energy consumption (e.g., no shape welding) } \\
\text { - } \quad \text { Minimal material input (e.g., through economically designed, force } \\
\text { flow-adapted reinforcement mesh) }\end{array}$ \\
\hline
\end{tabular}

\subsection{Development of the AMoRC Process}

In the following, the conceptual design of a novel 3D printing process for reinforced concrete, the so-called Additive Manufacturing of Reinforced Concrete (AMoRC), is presented. The proposed process is visualized in Figure 2. The process uses a combined print head, which allows for formwork-free depositing of concrete layers and uses a welding unit for simultaneous production of reinforcement. Here, the welding unit runs ahead of the concrete extrusion process and produces the spatial reinforcement mesh from prefabricated reinforcing bar segments. The concrete is placed around the reinforcing bars in such a way that they protrude a few centimeters from the printed concrete. The end zones of reinforcement bars sticking out of the concrete body can be used for joining/attaching a next row of bar segments in subsequent layers of the printing process. In this way, it is possible to create two- or three-dimensional reinforcement meshes, bridging interfaces between subsequent layers of concrete and to simultaneously encase them with concrete. The result of combining the 
intermittent welding production process and the continuous concrete extrusion process is AMoRC, a hybrid production process for RC structures.

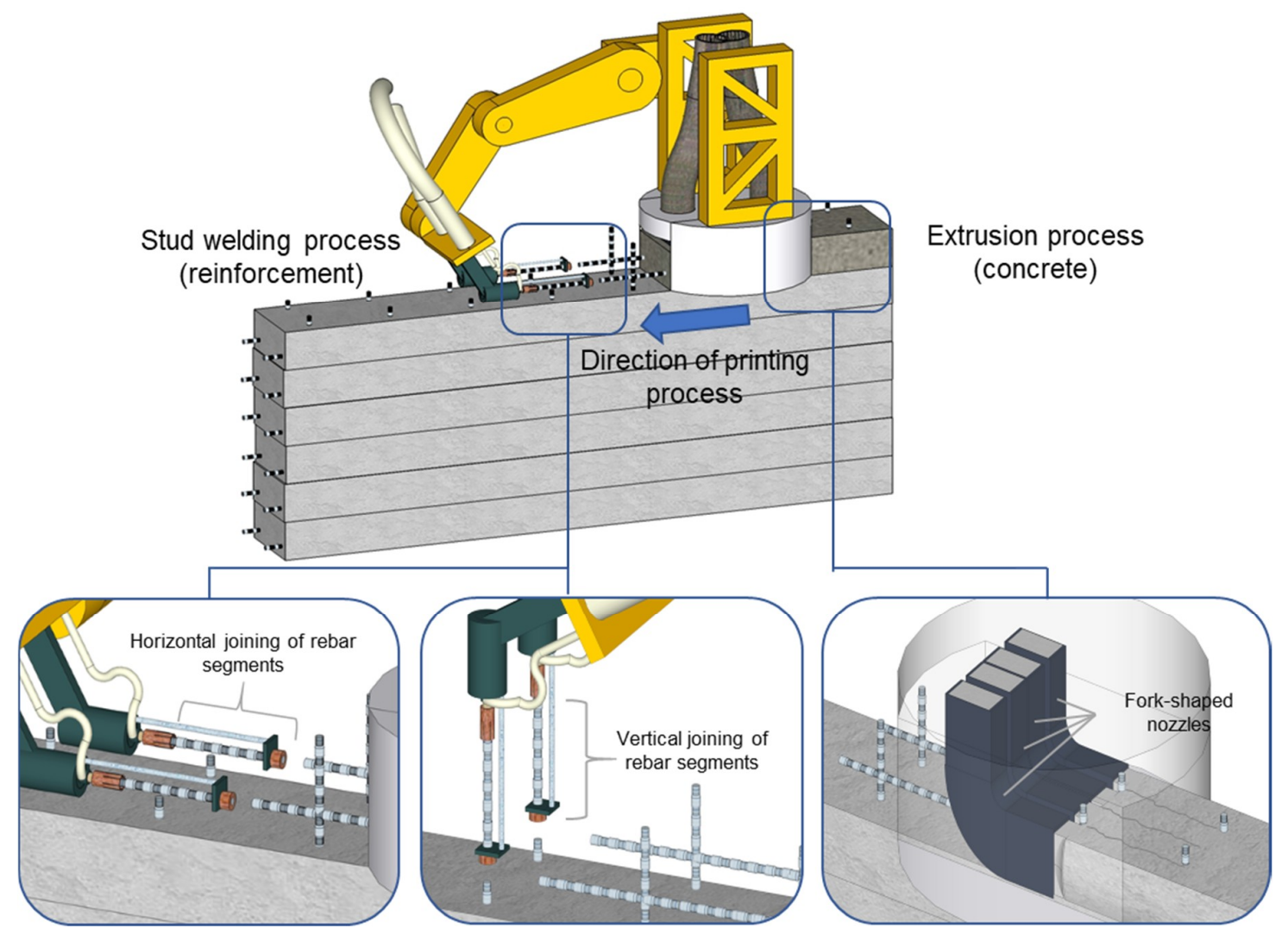

Figure 2. 3D printing process (AMoRC) for production of reinforced concrete including concrete extrusion and stud welding of reinforcement.

In contrast to processes that use shape welding for incremental built up of rebars [23,27], the reinforcement mesh in the AMoRC process is joined from segmented rebars of limited length (Figure 2). The length of the bar segments is adapted to the desired concrete layer thickness and concrete extrusion speed and is usually between 10 and $100 \mathrm{~cm}$. The joining of prefabricated bar segments drastically reduces the time required to produce the reinforcement compared to shape welding. Furthermore, significantly less energy is consumed and the lower heat accumulation results in significantly better material properties of the reinforcing steel. The welding processes used to join the prefabricated bar segments are either stud welding (enables straight joining of bars) (Figure 2), MAG welding (enables straight joints but also a deflection of bars) or a combination of both methods. The bar segments to be joined are kept ready in a magazine belonging to the print head (not shown in Figure 2), which enables the feeding of bars with different diameters. By using reinforcement of different diameters, it is possible to produce a reinforcement arrangement that is best suited to the internal flow of forces and, therefore, is very economical. In addition, welding joints allow us avoiding lap splices of the reinforcement, which may be possible weak points in a structure. While the concrete filaments are deposited parallel to underlying layers, the reinforcement pieces at the bar ends protruding from the concrete can be joined in both horizontal and vertical directions (Figure 2). Alternatively, any other angle between the bar axes of reinforcement and the concrete filament is possible, provided that the reinforcement mesh is oriented parallel to the center plane of the wall. 
The concrete is deposited around the reinforcement by means of a concrete print head, which consists of a fork-like arrangement of individual nozzles (Figure 2). Two nozzles are required for each layer of reinforcement to be encased with concrete. The distance between these nozzles can be adjusted to the current reinforcement diameter. Details on the development of the concrete print head, the nozzle arrangement and the geometry of the mouthpieces are explained in the following sections. The AMoRC process is particularly suitable to produce vertical free-standing, horizontally supported or slightly inclined structures. For overhanging, unsupported parts of a structure, the implementation of spraying shotcrete (cf. [22]) could be a conceivable extension of the AMoRC process.

\section{Applicability of Concept}

\subsection{Preliminary Works and Machine Setup}

In recent years, extensive preliminary work on additive manufacturing of non-reinforced concrete has been carried out at KU Leuven and RWTH Aachen University (e.g., on adhesion and delamination behavior of concrete layers), which confirms the general feasibility of the production method [32]. Concrete screw pumps with variable feed rates and various single and twin print heads are available for filament thicknesses of 1 to $4 \mathrm{~cm}$ and widths of 2 to $6 \mathrm{~cm}$. The concrete print heads are guided by a CNC machine which allows the production of structures with maximum dimensions of $1.5 \times 3.0 \times 1.25 \mathrm{~m}$. Various mix designs for extrudable concretes in a strength range from 20 to $80 \mathrm{~N} / \mathrm{mm}^{2}$ have been developed and current testing methods (Hägermann flow table, Vicat appartus) for assessing the fresh concrete properties and setting behavior are available. With the developed mix designs and equipment at hand, several geometrically complex demonstration objects were produced from unreinforced concrete (Figure 3a).

The Institute of Welding and Joining Technology of RWTH Aachen has comprehensive expertise in the use of different welding and joining methods as well as the characterization of properties of joined components. The welding of reinforcing steel can be carried out with different welding processes, whereby the MAG process (Figure 3b), flash welding and manual arc welding are the most frequently used. Particularly due to the high carbon content, the heat accumulation must be controlled when welding reinforcing steel, otherwise the properties of the steel will deteriorate. Since the abovementioned methods for welding reinforcement are time consuming, there is a need for a faster joining process. A modification of stud welding is, therefore, being pursued as a promising, timesaving joining method. For this purpose, comprehensive preliminary investigations were carried out. In stud welding, an electric arc is ignited between one end face of the stud and the workpiece. Both joining partners are melted and then joined through applying a low contact pressure. The stud welding process usually takes less than one second. It is frequently used in composite beams made of concrete and steel for installation of headed studs as shear connectors (Figure 3c). In addition, there is great experience in the additive production of steel by means of shape welding [33]. Extensive research has already been conducted on the use of different welding methods for metal 3D printing (Figure 3d). 

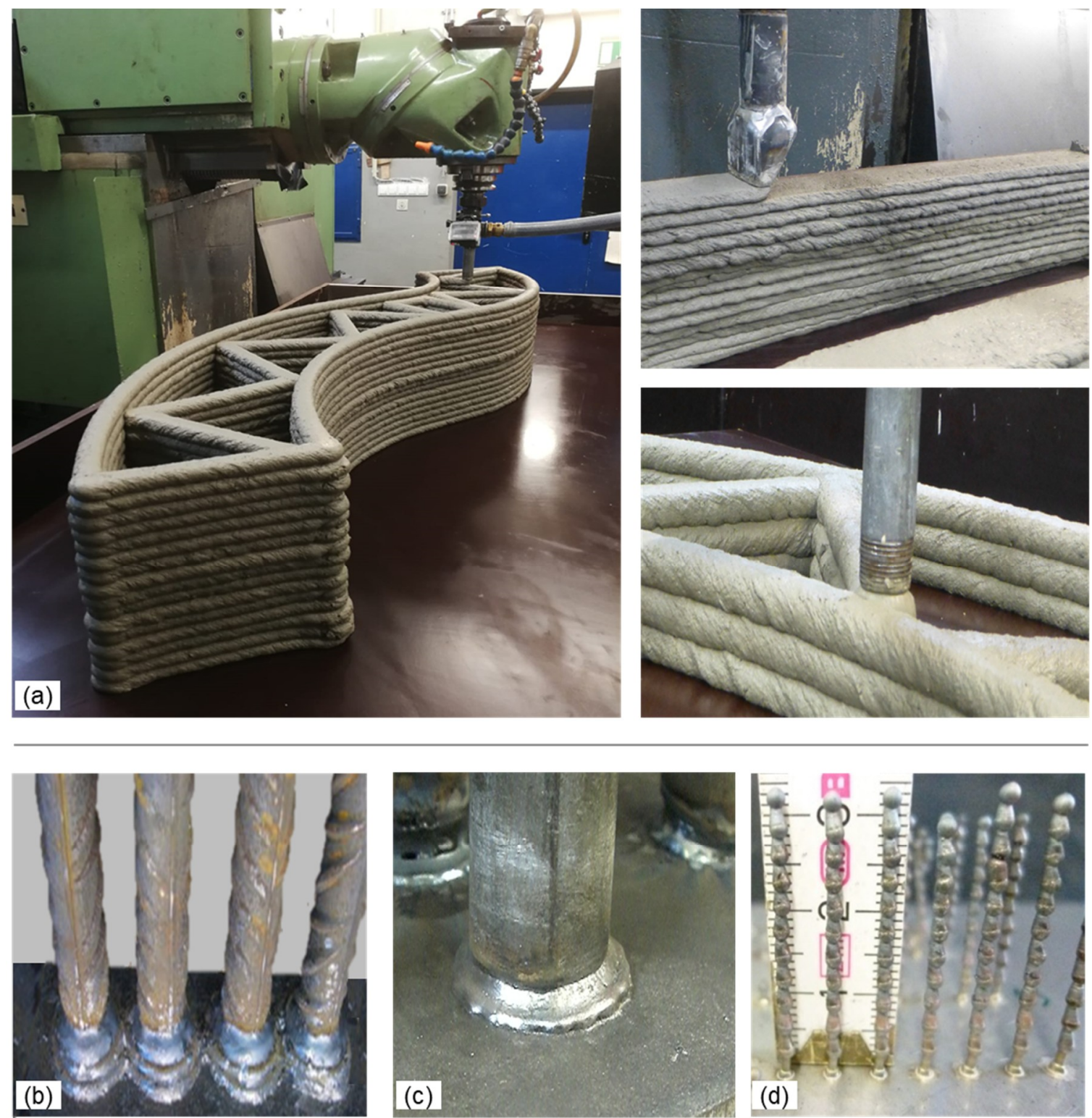

Figure 3. 3D printing of a non-reinforced demonstration objects at Institute of Structural Concrete of RWTH Aachen University (a), preliminary work for joining of reinforcement and additive manufacturing of steel at Institute for Joining and welding technology of RWTH Aachen University: MAG welding (b), stud welding (c), pin welding (d).

\subsection{Production of a $3 D$-Printed RC Wall Prototype}

To demonstrate the technical feasibility of the AMoRC process, a reinforced concrete wall panel has been printed in the lab (Figure 4a). As the technical implementation of a combined print head for concrete extrusion and joining of reinforcement has not been completed, so far, both processes were performed successively with the welding process preceding the concrete placement.

A fork-shaped print head with two nozzles was used for concrete extrusion (Figure $4 \mathrm{~b}$ ). Both nozzles had a rectangular opening cross section with a width of $45 \mathrm{~mm}$, producing filament thicknesses of $10 \mathrm{~mm}$ at a printing speed of $1.5 \mathrm{~m} / \mathrm{min}$. The distance between the nozzles was 1.5 times the reinforcement diameter. The total wall thickness was $100 \mathrm{~mm}$ with a reinforcement layer in the center of the wall cross section. The chosen concrete class was C70/85 and the concrete mix $\left(550 \mathrm{~kg} / \mathrm{m}^{3}\right.$ CEM I $52.5 \mathrm{R} ; 280 \mathrm{~kg} / \mathrm{m}^{3}$ water; $250 \mathrm{~kg} / \mathrm{m}^{3}$ fly ash; $1172 \mathrm{~kg} / \mathrm{m}^{3}$ aggregate with a maximum grain size of $4 \mathrm{~mm}$ ), with a water-binder ratio of 0.43 deliberately chosen simply for the reproducibility of the 
presented investigations. In the Hägermann flow table test, the concrete showed a spread flow diameter of $10.2 \mathrm{~cm}$ without shocks and $15.5 \mathrm{~cm}$ after 15 shocks immediately after mixing. The setting time of the concrete was $135 \mathrm{~min}$ determined with a Vicat apparatus. The time dependent fresh concrete properties are given in Figure 5. Highly ductile reinforcing steel B500 B with a diameter of $8 \mathrm{~mm}$ was used as reinforcement of the prototype. During the production of the demonstrator, only the concrete print head was automatically guided by a CNC machine, while the welding process was carried out manually. In the future, this will either be done by a robot with stud welding gun operating independently of the concrete print head or by a new type of print head combining welding and concrete extrusion process (see Figure 2).
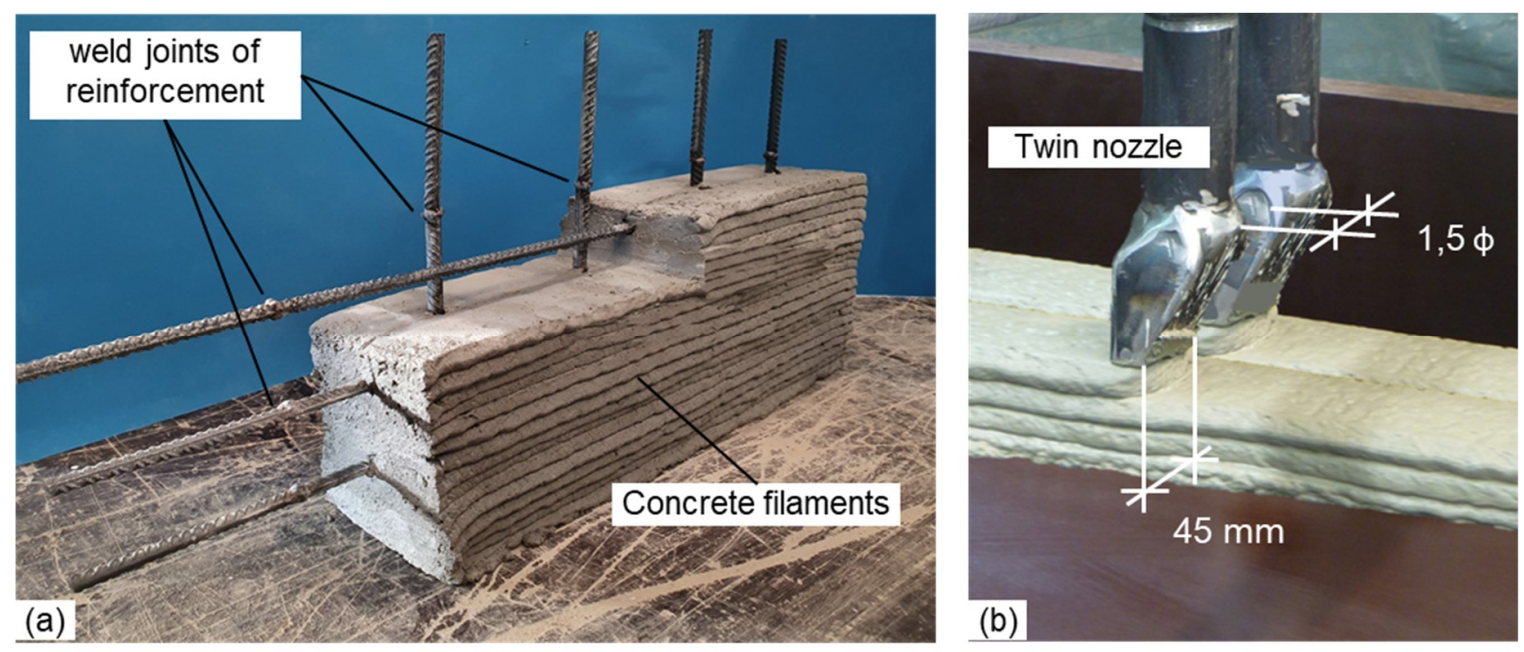

Figure 4. Demonstrator produced with the AMoRC process (a), concrete placement with twin nozzle (b).

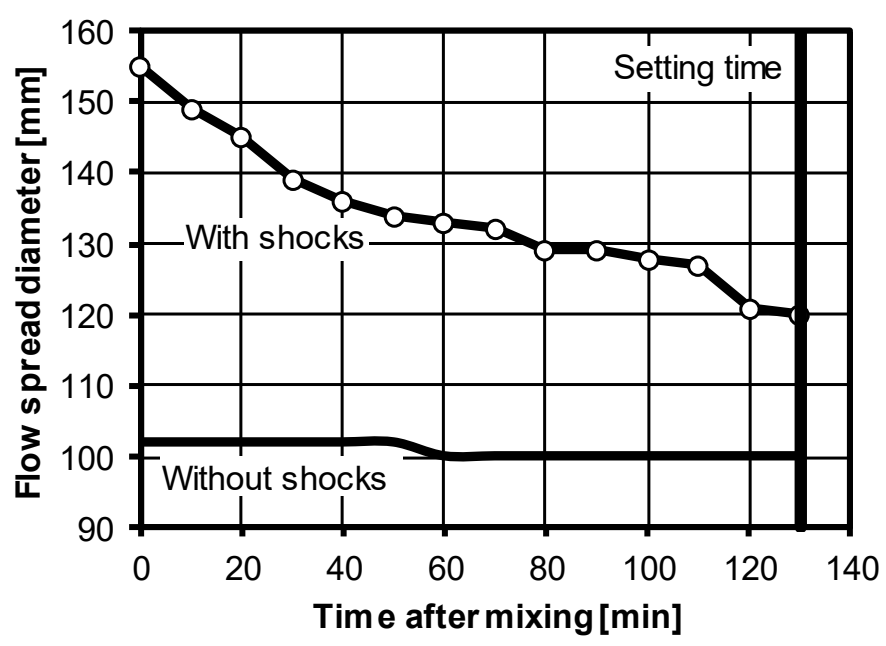

Figure 5. Spread diameter of Hägermann flow table test with increasing time. The dotted line shows values after 15 shocks and the continuous line without shocks.

\subsection{Outlook to Envisaged Investiagtions}

In order to make the AMoRC process ready for practical application on construction sites and in prefabrication plants, future works are planned addressing, on the one hand, the investigation of mechanical properties of the additively produced composite material and, on the other hand, the combination of concrete extrusion and stud welding process within a hybrid print head.

The aim is to setup a fully automated high-speed process suitable for production of members with wall thicknesses which are common in reinforced concrete construction, and reinforcement 
arrangements with at least one reinforcement layer per outer surface. For this purpose, fork-shaped, multi-nozzle extrusion heads for layer thicknesses of 50-100 mm and filament widths of 180 to $240 \mathrm{~mm}$ are to be developed (Figure 6a). An important objective is to ensure merging of concrete fed from individual nozzles within one continuous filament. In this context, the spacing of adjoining nozzles plays a crucial role. Preliminary investigations with the existing nozzle geometries (Figure 4) and feed rates show that defects can occur near the reinforcement if the nozzle spacing is chosen too large. During demonstrator production, clear defects were observed if the spacing of nozzles exceeded twice the reinforcement diameter (Figure $6 b$ ). In this context it is important to highlight that typical wall reinforcement usually has horizontal and vertical reinforcement that needs to pass between the nozzle gaps. If these bars are of the same diameter, then the gap needs to be more than two times bar diameter. There are different ways to face this aspect; for instance, using flexible nozzles with small gap spacing which allow the bars to squeeze through or implementing print heads with separate gaps for horizontal and vertical reinforcement. In addition, there are encouraging results, that defects reduce significantly when operating at higher feed rates. Besides a detailed investigation of these aspects, investigations into the bond properties of encased rebars are planned for both the horizontal and vertical reinforcement direction.

Furthermore, the combination of the printhead with additional features to actively control fresh concrete properties and devices to ensure adequate concrete interface quality will be investigated.

(a) concrete fed in individual

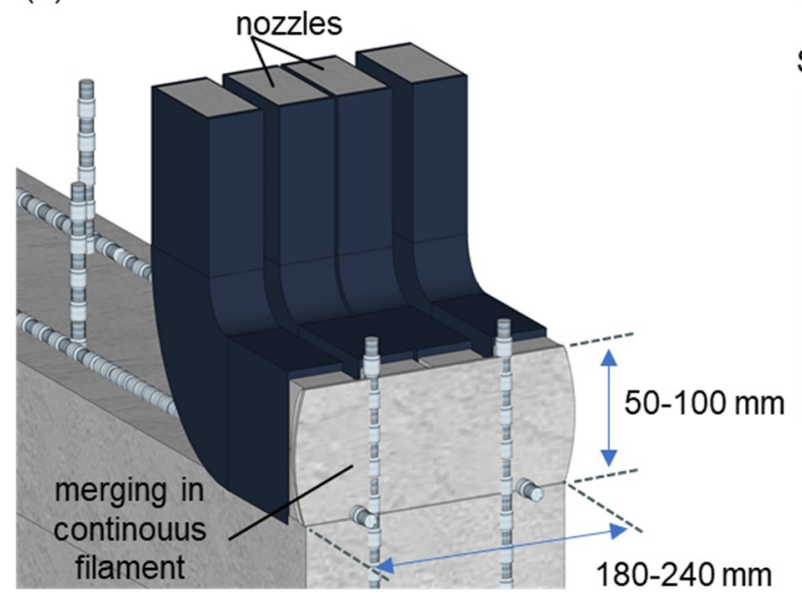

(b)

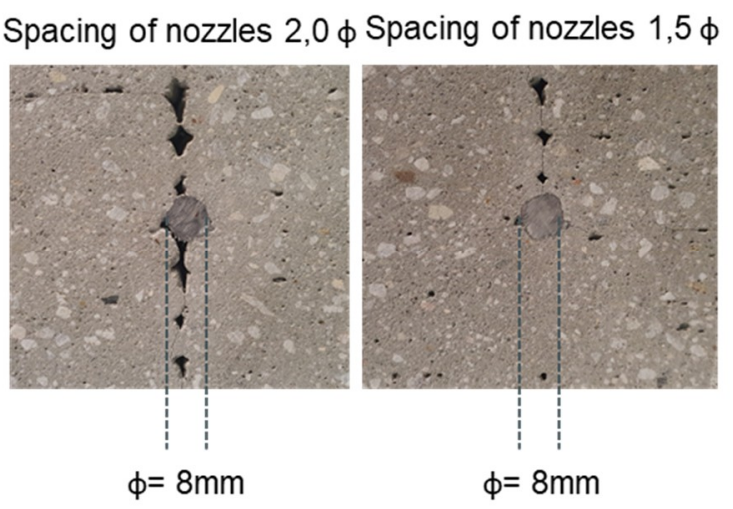

Figure 6. Multi-nozzle print head for wall thicknesses up to $240 \mathrm{~mm}$ and two reinforcement layers (a), influence of nozzle spacing on defects near the reinforcement (b).

In the field of welding technology, systematic research into modified arc stud welding for joining reinforcement is planned. In addition to assessing the quality of the material connection (hardening of steel, geometric parameters), the development of various possibilities of joining bars of different diameters at any desired angles in space play an important role. To evaluate the material properties of the steel, tensile and bending tests, macrosections and hardness tests of the joining zones are carried out. Finally, the methods developed for concrete extrusion and steel joining are combined into a simultaneously running hybrid process.

\section{Assessing Benefits and Potential of the AMoRC Process}

The most plausible way to assess the potential of the AMoRC process is benchmarking it against other digital fabrdication processes. Figure 7a shows a reinforced concrete wall of $240 \mathrm{~mm}$ wall thickness, reinforced with bars of $12 \mathrm{~mm}$ diameter and a mesh size of $250 \mathrm{~mm}$ in horizontal and vertical direction. This RC wall panel will be used as benchmark problem. 
(a)

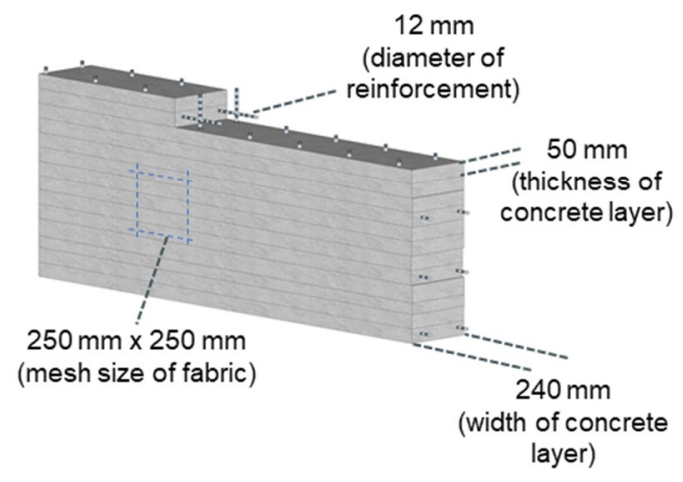

(b)

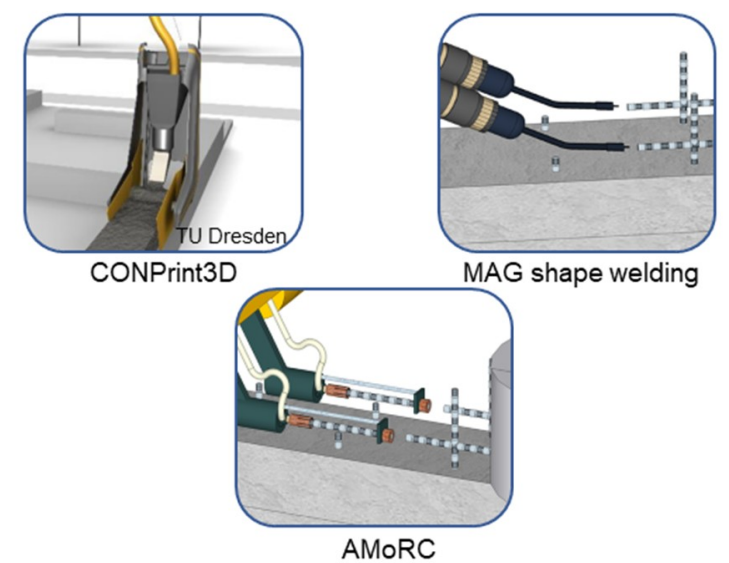

Figure 7. Benchmark problem (a) and comparison of selected processes (b).

A selection of digital fabrication processes to be compared to each other is given in Figure $7 \mathrm{~b}$. CONPrint3D of TU Dresden [34] is one of the most powerful concrete printing processes in the world and can be used for production of non-reinforced concrete wall panels. It can be carried out at speeds of up to $0.15 \mathrm{~m} / \mathrm{s}$, with layers of $5 \mathrm{~cm}$ thickness and $24 \mathrm{~cm}$ in width. The resulting production rate of $27 \mathrm{~m}^{2}$ of non-reinforced wall surface per hour [34] is approximately four times shorter than in traditional masonry construction. However, it has to be kept in mind that integration of reinforcement is not addressed in this process.

By contrast, the multi-arm printing technology based on MAG shape welding of reinforcement $[23,29]$ and extrusion of concrete allows producing reinforced concrete panels. However, this process is much slower. Here, the speed of shape welding (melting rate of $1 \mathrm{~kg} / \mathrm{h}$ ) is the limiting factor for the overall process speed. If we assume the benchmark ( $24 \mathrm{~cm}$ wall thickness made up of two layers of reinforcement, mesh size of $25 \mathrm{~cm}$ and bar diameter of $12 \mathrm{~mm}$ ) to be produced by two independently operating welding torches (Figure $7 \mathrm{~b}$ ), the total process merely allows the production of $0.14 \mathrm{~m}^{2}$ wall surface per hour. Such a process can hardly be implemented economically because the welding process would considerably impede the concrete extrusion process or even make its execution impossible.

In contrast, the AMoRC process allows for production speeds comparable to those of the CONPrint3D process, however for reinforced instead of plain concrete. The reason is that concrete extrusion and stud welding of a reinforcement can be fully synchronized through the suitable selection of reinforcement segment length and concrete deposition speed. Assuming the AMoRC process to operate with two-stud welding guns (Figure $7 \mathrm{~b}$ ), the reinforcement mesh to be joined from $25-\mathrm{cm}$ long bar segments in both a horizontal and vertical direction (this corresponds to 32 reinforcement joints per square meter and reinforcement layer) with one weld spot per reinforcement layer to be produced within $4 \mathrm{~s}$ ( $1 \mathrm{~s}$ welding time, $3 \mathrm{~s}$ travel distance to the next joint), the welding production speed of the AMoRC process is $28 \mathrm{~m}^{2}$ per hour. If we consider the concrete printing unit of the AMoRC process to have comparable performance data like the CONPrint3D $\left(27 \mathrm{~m}^{2}\right.$ wall area per hour; filament height $5 \mathrm{~cm}$; printing speed $0.15 \mathrm{~m} / \mathrm{s}$ ) we end up with merely identical feed rates for both processes.

This is one great advantage of the AMoRC process: it enables the full synchronization of the intermittent welding process and the continuous concrete printing process, thus realizing optimum production speed for the overall hybrid process.

\section{Conclusions}

In this paper, the conceptual design of a novel process for the digital fabrication of reinforced concrete was presented. In the AMoRC process, segmented steel reinforcing bars are joined to form a three-dimensional reinforcement mesh using a stud welding process and simultaneously encased with 
a concrete extrusion process. The development of the process is motivated through requirements of construction sites and prefabrication plants and oriented toward real-world application. Preliminary prototypical studies illustrate the basic feasibility of the AMoRC process, but also show the necessity of intensive future research to clarify open questions in the areas of process engineering (concrete extrusion, welding process) and structural performance of the printed composite material.

The decisive advantage of the developed method compared to previous approaches for 3D printing of reinforced concrete is the possibility to adjust the welding process and the concrete extrusion process for operation at identical feed rates. The synchronization of both processes allows them to be combined in one hybrid print head for the production of reinforced concrete.

Author Contributions: Conceptualization, M.C. and R.S.; methodology, M.C.; formal analysis, M.C. and J.U.; investigation, M.C. and J.U.; writing-original draft preparation, M.C.; writing-review and editing, J.U. and R.S; visualization, M.C.; supervision, M.C.; project administration, M.C.; funding acquisition, M.C. and R.S. All authors have read and agreed to the published version of the manuscript.

Funding: This research received no external funding.

Conflicts of Interest: The authors declare no conflict of interest.

\section{References}

1. Hull, C.W. The birth of 3D printing. Res.-Technol. Manag. 2015, 58, 25-30.

2. Calignano, F.; Manfredi, D.; Ambrosio, E.P.; Biamino, S.; Lombardi, M.; Atzeni, E.; Fino, P. Overview on additive manufacturing technologies. Proc. IEEE 2017, 105, 593-612. [CrossRef]

3. Schubert, C.; Van Langeveld, M.C.; Donoso, L.A. Innovations in 3D printing: A 3D overview from optics to organs. Br. J. Ophthalmol. 2014, 98, 159-161. [CrossRef] [PubMed]

4. Khoshnevis, B. Automated construction by Contour Crafting-Related robotics and information technologies. J. Autom. Constr. 2004, 13, 5-19. [CrossRef]

5. Lim, S.; Buswell, R.; Le, T.; Wackrow, R.; Austin, S.; Gibb, A.; Thorpe, T. Development of a viable concrete printing process. In Proceedings of the 28th International Symposium on Automation and Robotics in Construction (ISARC2011), Seoul, Korea, 29 June-2 July 2011; pp. 665-670.

6. Buswell, R.A.; de Silva, W.L.; Jones, S.Z.; Dirrenberger, J. 3D printing using concrete extrusion: A roadmap for research. Cem. Concr. Res. 2018, 112, 37-49. [CrossRef]

7. Mechtcherine, V.; Bos, F.P.; Perrot, A.; da Silva, W.L.; Nerella, V.N.; Fataei, S.; Roussel, N. Extrusion-based additive manufacturing with cement-based materials-Production steps, processes, and their underlying physics: A review. Cem. Concr. Res. 2020, 132, 106037. [CrossRef]

8. Tay, Y.W.D.; Panda, B.; Paul, S.C.; Noor Mohamed, N.A.; Tan, M.J.; Leong, K.F. 3D printing trends in building and construction industry: A review. Virtual Phys. Prototyp. 2017, 12, 261-276. [CrossRef]

9. Mechtcherine, V.; Nerella, V.N. Beton-3D-Druck durch selektive Ablage. Beton- Und Stahlbetonbau 2019, 114, 24-32. [CrossRef]

10. Mechtcherine, V.; Nerella, V.N.; Will, F.; Näther, M.; Otto, J.; Krause, M. Large-scale digital concrete construction-CONPrint3D concept for on-site, monolithic 3D-printing. Autom. Constr. 2019, 107, 102933. [CrossRef]

11. De Schutter, G.; Lesage, K.; Mechtcherine, V.; Nerella, V.N.; Habert, G.; Agusti-Juan, I. Vision of 3D printing with concrete-Technical, economic and environmental potentials. Cem. Concr. Res. 2018, 112, 25-36. [CrossRef]

12. Van Der Putten, J.; De Schutter, G.; Van Tittelboom, K. The effect of print parameters on the (micro) structure of $3 \mathrm{D}$ printed cementitious materials. In RILEM International Conference on Concrete and Digital Fabrication; Springer: Cham, Switzerland, 2018; pp. 234-244.

13. Bos, F.; Wolfs, R.; Ahmed, Z.; Salet, T. Additive manufacturing of concrete in construction: Potentials and challenges of 3D concrete printing. Virtual Phys. Prototyp. 2016, 11, 209-225. [CrossRef]

14. Wolfs, R.; Suiker, A. Structural failure during extrusion-based 3D printing processes. Int. J. Adv. Manuf. Technol. 2019, 104, 565-584. [CrossRef]

15. Asprone, D.; Menna, C.; Bos, F.P.; Salet, T.A.; Mata-Falcón, J.; Kaufmann, W. Rethinking reinforcement for digital fabrication with concrete. Cem. Concr. Res. 2018, 112, 111-121. [CrossRef] 
16. Sevenson, B. Shanghai-based WinSun 3D Prints 6-Story Apartment Building and an Incredible Home. 2020. Available online: https://3dprint.com/38144/3Dprinted-apartmentbuilding/ (accessed on 2 May 2020).

17. Apis Cor. Apis Cor-Construction Technology. 2020. Available online: http://apis-cor.com/en/faq/ texnologiya-stroitelstva (accessed on 2 May 2020).

18. Bos, F.; Wolfs, R.; Ahmed, Z.; Salet, T. Large scale testing of digitally fabricated concrete (DFC) elements. In RILEM International Conference on Concrete and Digital Fabrication; Springer: Cham, Switzerland, 2018; pp. 129-147.

19. Asprone, D.; Auricchio, F.; Menna, C.; Mercuri, V. 3D printing of reinforced concrete elements: Technology and design approach. Constr. Build. Mater. 2018, 165, 218-231. [CrossRef]

20. Scott, C. Chinese Construction Company 3D Prints an Entire Two-Story House On-Site in 45 Days. 2016. Available online: https://3dprint.com/138664/huashangtengda-3Dprint-house/ (accessed on 2 May 2020).

21. Lindemann, H.; Gerbers, R.; Ibrahim, S.; Dietrich, F.; Herrmann, E.; Dröder, K.; Raatz, A.; Kloft, H. Development of a shotcrete 3D-printing (SC3DP) technology for additive manufacturing of reinforced freeform concrete structures. In RILEM International Conference on Concrete and Digital Fabrication; Springer: Cham, Switzerland, 2018; pp. 287-298.

22. Kloft, H.; Hack, N.; Mainka, J.; Brohmann, L.; Herrmann, E.; Ledderose, L.; Lowke, D. Additive Fertigung im Bauwesen: Erste 3-D-gedruckte und bewehrte Betonbauteile im Shotcrete-3-D-Printing-Verfahren (SC3DP). Bautechnik 2019, 96, 929-938. [CrossRef]

23. Mechtcherine, V.; Nerella, V.N. Integration der Bewehrung beim 3D-Druck mit Beton. Beton-und Stahlbetonbau 2018, 113, 496-504. [CrossRef]

24. Hack, N.; Lauer, W.V. Mesh-Mould: Robotically Fabricated Spatial Meshes as Reinforced Concrete Formwork. Archit. Des. 2014, 84, 44-53. [CrossRef]

25. Bos, F.P.; Ahmed, Z.Y.; Wolfs, R.J.; Salet, T.A. 3D printing concrete with reinforcement. In High Tech Concrete: Where Technology and Engineering Meet; Springer: Cham, Switzerland, 2018; pp. 2484-2493.

26. Khoshnevis, B.; Bekey, G. Automated Construction Using Contour Crafting-Applications on Earth and Beyond; Nist Special Publication; The International Association for Automation and Robotics in Construction: London, UK, 2003; pp. 489-494.

27. Classen, M.; Gallwoszus, J.; Kopp, M.; Schäfer, J. Kleinskalige Pin-Verbundmittel für den Stahl-Beton-Verbundbau. Bauingenieur 2015, 90, 200-208.

28. Classen, M.; Herbrand, M.; Kueres, D.; Hegger, J. Derivation of design rules for innovative shear connectors in steel-concrete composites through the systematic use of non-linear finite element analysis (FEA). Struct. Concr. 2016, 17, 646-655. [CrossRef]

29. Reisgen, U.; Willms, K.M.; Schäfer, J.; Türker, M.; Hegger, J.; Classen, M.; Feldmann, M.; Kopp, M. Investigations on small-scaled welded structures of austenitic stainless steel. Kov. Mater. 2019, 57, 397-405. [CrossRef]

30. Brell-Cokcan, S.; Lublasser, E.; Haarhoff, D.; Kuhnhenne, M.; Feldmann, M.; Pyschny, D. Zukunft Robotik-Automatisierungspotentiale im Stahl- und Metallleichtbau. Stahlbau 2017, 86, 225-233. [CrossRef]

31. Kampf, M. Verbindende Verfahren. In Handbuch Maschinenbau; Böge, A., Böge, W., Eds.; Springer: Vieweg, Wiesbaden, 2017.

32. Classen, M.; Adam, V.; Hillebrand, M. Torsion Test Setup to Investigate Aggregate Interlock and Mixed Mode Fracture of Monolithic and 3D-Printed Concrete; FIB Symposium: Krakow, Poland, 2019.

33. Reisgen, U.; Sharma, R.; Oster, L. Plasma Multiwire Technology with Alternating Wire Feed for Tailor-Made Material Properties in Wire and Arc Additive Manufacturing. Metals 2019, 9, 745. [CrossRef]

34. Näther, M.; Nerella, V.N.; Krause, M.; Kunze, G.; Mechtcherine, V.; Schach, R. Beton-3D-Druck -Machbarkeitsuntersuchungen zu Kontinuierlichen und Schalungsfreien Bauverfahren Durch 3D-Formung von Frischbeton; Abschlussbericht zum ZukunftBau-BMVBS-Projekt TU: Dresden, Germany, 2017.

(C) 2020 by the authors. Licensee MDPI, Basel, Switzerland. This article is an open access article distributed under the terms and conditions of the Creative Commons Attribution (CC BY) license (http://creativecommons.org/licenses/by/4.0/). 